\title{
IMPLEMENTAÇÃO DO ATENDIMENTO EDUCACIONAL ESPECIALIZADO E A FORMAÇÃO DOS GESTORES NA CAPITAL AMAZONENSE
}

\author{
APLICACIÓN DE ESPECIALISTA DE SERVICIO DE EDUCACION Y \\ FORMACION DE GERENTES EN MANAUS
}

\author{
IMPLEMENTATION OF THE EDUCATIONAL SERVICE AND SPECIALIZED \\ TRAINING OF MANAGERS IN MANAUS
}

\author{
Samuel VINENTE ${ }^{1}$ \\ Sônia Selena Baçal de OLIVEIRA ${ }^{2}$
}

\begin{abstract}
RESUMO: O estudo analisou as políticas de inclusão escolar em Manaus com ênfase na formação de gestores. A pesquisa foi de abordagem qualitativa, de caráter documental, na qual foram analisados documentos publicados entre 2008 e 2014. Os dados apontaram que o número de salas de recursos multifuncionais ainda é insuficiente para atender a demanda de estudantes público-alvo da educação especial matriculados. Verificou-se que dos 487 gestores, $24 \%$ são do gênero masculino e $76 \%$ do gênero feminino. Destes, $93 \%$ são servidores estatutários, $1 \%$ temporário e não foi possível obter informações dos outros 6\%. Quanto à formação dos gestores para atuação em sistemas de ensino mais inclusivos, verificou-se que há crescente demanda tendo em vista que parte destes não possuem formação inicial ou continuada na área da educação e educação especial. Espera-se que os resultados possibilitem a obtenção de um panorama sobre a implementação das políticas de inclusão e apontem possibilidades de intervenção na região Amazônica.
\end{abstract}

PALAVRAS-CHAVE: Educação Especial. Formação de gestores. Política educacional. Manaus.

RESUMEN: El estudio analiza las políticas de inclusión escolar en Manaus con énfasis en la formación de directivos. La investigación fue enfoque cualitativo de carácter documental, que se publicaron los documentos fueron analizados entre 2008 y 2014. Los datos mostraron que el número de salas de recursos multifuncionales sigue siendo insuficiente para satisfacer la demanda del público objetivo de los estudiantes de educación especial matriculados. Se encontró que de 487 gerentes, el $24 \%$ eran mujeres y el $76 \%$ varones. De éstos, el $93 \%$ eran funcionarios del gobierno, el 1\% temporales y no pudo obtener información de los otros 6\%. En cuanto a la formación de directivos para trabajar en los sistemas educativos más inclusivos, se encontró que existe una demanda creciente en función de estos que no tienen la educación inicial o continua en la educación y la educación especial. Se espera que los resultados hacen

\footnotetext{
${ }^{1}$ Mestrando do Programa de Pós-Graduação em Educação Especial pela Universidade Federal de São Carlos (UFSCar). Bolsista da Fundação de Amparo à Pesquisa no Estado do Amazonas (FAPEAM). Integrante do Grupo de Estudos e Pesquisas - Políticas Públicas e Educação (GPPE) e do Grupo de Estudos e Pesquisas sobre a Escolarização da Pessoa com Deficiência (GEPEPD). Email: samueljunior.ns@gmail.com

${ }^{2}$ Doutora em Educação pela Universidade Estadual de Campinas (UNICAMP). Mestre em Educação pela Universidade de São Paulo (USP). Professora do Departamento de Administração e Planejamento da Faculdade de Educação da Universidade Federal do Amazonas (UFAM). Email: selenebacal@ uol.com.br
} 
posible la obtención de una visión general de la aplicación de las políticas de inclusión y posibilidades de puntos de intervención en la región amazónica

PALAVRAS CLAVE: La educación especial. Los administradores de formación. La política educativa. Manaus.

ABSTRACT: The study looked at the school inclusion policies in Manaus with emphasis on training managers. The research was qualitative approach of documentary character, which published papers were analyzed between 2008 and 2014. The data showed that the number of multi-functional resource rooms is still insufficient to meet the demand of target audience of special education students enrolled. It was found that of 487 managers, $24 \%$ were male and $76 \%$ female. Of these, 93\% were government servants, $1 \%$ temporary and could not get information from the other $6 \%$. As for the training of managers to work in more inclusive education systems, it was found that there is growing demand in view of these that have no initial or continuing education in the field of education and special education. It is expected that the results make it possible to obtain an overview of the implementation of inclusion policies and point possibilities of intervention in the Amazon region.

KEYWORDS: Special Education. Training Managers. Educational policy.

\section{Introdução}

A presente investigação integrou as ações do Grupo de Estudos e Pesquisas Políticas Públicas e Educação (GPPE), encontrando-se cadastrada no Departamento de Apoio à Pesquisa da Universidade Federal do Amazonas (UFAM) sob o código PIB-SA 0139/2014, a qual foi desenvolvida com apoio da Fundação de Amparo à Pesquisa no Estado do Amazonas (FAPEAM).

O Atendimento Educacional Especializado (AEE) é assegurado em inúmeros dispositivos legais, os quais destacam-se: a Constituição Federal (BRASIL, 1988), o Estatuto da Criança e do Adolescente - ECA (BRASIL, 1990), a Lei de Diretrizes e Bases (BRASIL, 1996), a Política Nacional de Educação Especial na Perspectiva da Educação Inclusiva (BRASIL, 2008), o Decreto $n^{\circ} 7.611$ (BRASIL, 2011) e o Plano Nacional de Educação - PNE (BRASIL, 2014).

No campo das políticas educacionais, destaca-se a implementação de inúmeros acordos firmados entre o Brasil e diversos organismos multilaterais, principalmente na década de 1990. Nesse contexto mencionamos a publicação da Declaração Mundial sobre Educação para Todos (1990), resultante de uma conferência internacional realizada na Tailândia e a Declaração de Salamanca - sobre princípios, políticas e práticas na área das necessidades educativas especiais (1994), resultante de outra 
conferência realizada na Espanha em 1994.

No tocante às políticas de educação especial no Brasil, Garcia e Michels (2011) contextualizam que a Política Nacional de Educação Especial (1994) orientou ações com base em princípios específicos tais como normalização, integração, individualização, interdependência, construção do real, efetividade dos modelos de atendimento educacional e legitimidade. Nesse contexto percebe-se que em diferentes momentos históricos foram construídas diferentes alternativas, ou seja, enquanto anteriormente se discutia a integração hoje o debate é sobre a inclusão escolar.

Muitos dos trabalhos na literatura científica da área apontam uma expressividade em estudos sobre a formação inicial e continuada de professores (MATOS; MENDES, 2012; LAGO, ALMEIDA, 2014; VILARONGA; MENDES, 2014), porém ainda temos poucos pesquisadores que discutem as questões relacionadas à formação de gestores e outros profissionais que atuam juntamente com estudantes Público-Alvo da Educação Especial (PAEE). Entende-se então que averiguar como as diretrizes nacionais implementam-se em âmbito local torna-se fundamental para que a escola rediscuta seu processo de formação e o real sentido da educação para todos.

A definição do AEE a partir da publicação do Decreto $n^{\circ} 7.611$, de 17 de novembro de 2011, é entendida como o “[...] conjunto de atividades, recursos de acessibilidade e pedagógicos organizados institucional e continuamente [...]” (BRASIL, 2011 , art. $2^{\circ}, \S 1^{\circ}$ ), podendo ser prestado de forma complementar (aos estudantes com deficiência e transtornos globais do desenvolvimento) e suplementar (aos estudantes com altas habilidades ou superdotação).

Os objetivos do AEE baseiam-se em: (a) prover condições de acesso, participação e aprendizagem dos estudantes PAEE e a garantia de serviços de apoio especializado; (b) garantia da transversalidade da educação especial ${ }^{3}$ no ensino regular; (c) desenvolvimento de recursos didáticos e pedagógicos para eliminação das barreiras; e (d) assegurar condições para a continuidade dos estudos nos demais níveis, etapas e modalidades de ensino (BRASIL, 2011, art. $3^{\circ}$, incisos I a IV).

As salas de recursos multifuncionais são classificadas em dois grupos: (a) tipo I - possuem diversos recursos para o AEE de estudantes com deficiência, transtornos globais e altas habilidades; e, (b) tipo II - possuem os mesmos recursos das salas do tipo

${ }^{3}$ A educação especial é definida na Lei de Diretrizes e Bases (BRASIL, 1996), em redação dada pela Lei no 12.796 , de abril de 2013 como a "[...] a modalidade de educação escolar oferecida preferencialmente na rede regular de ensino, para educandos com deficiência, transtornos globais do desenvolvimento e altas habilidades ou superdotação" (BRASIL, 2013, art. 58). 
II, entretanto são acrescidos recursos pedagógicos e de acessibilidade para estudantes com deficiência visual (BRASIL, 2010).

Na capital amazonense, segundo dados do Ministério da Educação - MEC sobre a implantação das salas de recursos multifuncionais, dispõe-se de 65 salas de recursos multifuncionais do tipo 1 (20 na dependência estadual e 45 na municipal) e 11 salas do tipo II (sendo 10 na dependência estadual e 1 na municipal). Levando-se em consideração o quantitativo de estudantes PAEE matriculados, pode-se aferir que esse número é insuficiente para garantir a oferta do AEE no município.

Em contrapartida, se torna inviável implantar mais salas se não há profissionais preparados para o trabalho pedagógico nesses espaços. Nessa perspectiva, para que a escola se torne inclusiva é necessário que novas formas de reconfiguração do espaço escolar redimensionem as práticas e as vivências da equipe escolar. Assim sendo, não se concebe que apenas professores sejam preparados, pois inúmeras pesquisas apontam que somente isso não inviabiliza a proposta da escola inclusiva (VINENTE, 2012; LAGO; ALMEIDA, 2014; MATOS; MENDES, 2015), mas, que os demais profissionais também recebam formação, inclusive os gestores.

Ao se compreender os inúmeros avanços das políticas de inclusão escolar no campo jurídico já pode-se observar a configuração das fases dos processos de formulação e agenda das políticas púbicas, tornando-se então necessário que estudos sejam desenvolvidos para pesquisar sobre a execução das ações, bem como avaliar e monitorar tais aspectos da inclusão escolar que se implementam de formas distintas em cada contexto escolar.

Nesse sentido, para o desenvolvimento deste estudo foram elaborados os seguintes questionamentos: (a) como vem sendo implementado no município a política de educação especial para o atendimento educacional especializado de estudantes PAEE? (b) como caracteriza-se o perfil e a formação dos gestores municipais que atuam na secretaria de educação? Assim sendo, o trabalho objetiva discutir como vem sendo implementadas as políticas de inclusão na rede pública municipal da cidade de Manaus com ênfase na formação de gestores.

\section{Método}

O método apresentado nesse trabalho encontra-se subdividido em: (a) delineamento do estudo; (b) local; (c) Estrutura organizacional da Secretaria Municipal de Educação; e, (d) fontes documentais. 


\section{Delineamento do estudo}

O estudo foi realizado mediante uma abordagem qualitativa em educação, observando o materialismo histórico-dialético por meio das contradições entre as políticas públicas e os desafios da implantação das mesmas nos sistemas de ensino (FAZENDA, 2008; OLIVEIRA; OLIVEIRA, 2011). Foram analisados documentos publicados entre o período de 2008 a 2014, o que possibilitou o estudo sobre o conceito de inclusão adotado nos dispositivos legais e sua implementação no cotidiano escolar.

Segundo Sanchez Gamboa (1998), as abordagens de pesquisa são teorias em ação e identificam as diversas formas de concepção do objeto e do sujeito no processo de construção do conhecimento. O materialismo histórico dialético, método o qual os pesquisadores concebem o mundo permitiu a releitura dos clássicos, tendo como base a contradição verificada entre o que foi explicitado nos documentos oficiais e o que realmente se legitima no cotidiano escolar.

\section{Local}

O estudo foi desenvolvido na rede municipal de ensino da cidade de Manaus. A cidade, segundo dados do Instituto Brasileiro de Geografia e Estatística (IBGE, 2010) possui no ano de 2015 uma população estimada em 2.057.711 habitantes, o que corresponde a uma densidade demográfica de 158,6\% (hab./ $\left.\mathrm{km}^{2}\right)$. A capital amazonense possui uma área territorial de $11.401,092 \mathrm{~km}^{2}$ e está localizada à margem esquerda do Rio Negro (IBGE, 2010), sendo a sexta capital mais populosa do Brasil.

Segundo dados do Censo Escolar da Educação Básica referentes ao ano de 2013, levantados pelo Instituto Nacional de Estudos e Pesquisas Educacionais Anísio Teixeira (INEP), a cidade possui 62.017 estudantes matriculados na Educação Infantil, 350.259 no Ensino Fundamental, 98.034 no Ensino Médio, 11.928 no Ensino Profissional de Nível Técnico, e 39.973 nas turmas de Educação de Jovens e Adultos presencial e semipresencial (INEP, 2014).

Desse quantitativo de matrículas em quatro dependências administrativas (federal, estadual, municipal e privada), os estudantes PAEE com matrículas ativas na cidade de Manaus encontram-se na Educação Infantil (387), nos anos iniciais (223) e finais (50) do Ensino Fundamental, no Ensino Médio (173), na Educação Profissional de Nível Técnico (6) e na Educação de Jovens e Adultos (875). 


\section{Estrutura organizacional da Secretaria Municipal de Educação}

A Secretaria Municipal de Educação é constituída por: (a) órgãos colegiados; (b) órgãos de assistência e assessoramento; (c) órgãos de apoio à gestão e, (d) órgãos de atividades finalísticas. Os cargos de gerência e assessoramento do sistema municipal de ensino são ocupados por um secretário, um subsecretário, diretores de departamentos, assessores técnicos, chefes das divisões e assessores (MANAUS, 2013).

Segundo a Lei Delegada n $^{\circ} 13$, de 31 de julho de 2013, a SEMED possui as seguintes finalidades:

I - formular, supervisionar, coordenar e avaliar a Política Municipal de Educação, em conformidade com a Lei de Diretrizes e Bases da Educação Nacional;

II - planejar, coordenar, controlar e executar atividades para prover os recursos necessários, métodos e profissionais a fim de oferecer à sociedade serviços educacionais de elevado padrão de qualidade, adequados às diversas faixas etárias e níveis - educação infantil e ensino fundamental -, garantindo dignidade e qualidade de vida aos cidadãos do Município. (MANAUS, 2013, n.p.).

A estrutura organizacional da Secretaria é composta por zonas distritais, de forma que há setores dentro da secretaria que atendem as diferentes regiões da zona urbana e zona rural da cidade de Manaus. A zona urbana é atendida pelas regiões distritais a seguir: (a) sul; (b) centro-sul; (c) oeste; (d) centro-oeste; (e) norte I; (f) norte II; (g) leste I; e (h) leste II. A zona rural da cidade é atendida pelas zonas distritais rodoviária e ribeirinha. A Tabela 1 ilustra a divisão do organograma estrutural dos gestores vinculados à Secretaria:

Tabela 1: Número de Gestores das zonas distritais da rede pública municipal de ensino (2015)

\begin{tabular}{lccccccccc}
\hline Sul & $\begin{array}{c}\text { Centro- } \\
\text { sul }\end{array}$ & Oeste & $\begin{array}{c}\text { Centro- } \\
\text { oeste }\end{array}$ & Norte I & $\begin{array}{c}\text { Norte } \\
\text { II }\end{array}$ & Leste & Leste & Rodoviária & Ribeirinha \\
& 23 & 53 & 26 & 62 & 55 & 66 & 69 & 35 & 52
\end{tabular}

Fonte: Elaboração própria, com base nos dados do Cadastro Escolar (SEMED, 2014)

Conforme pode-se observar na Tabela 1 as zonas norte e leste por serem as zonas mais populosas da cidade, comportam mais escolas para atender à demanda de estudantes matriculados. As zonas que compõe a área rural representam 87 (oitenta e sete) escolas voltadas para a população do campo e a população ribeirinha. 


\section{Fontes documentais}

Foram consultados os dados do MEC, do Censo Escolar do Instituto Nacional de Estudos e Pesquisas Anísio Teixeira (INEP) e do Cadastro Escolar da secretaria (SEMED, 2014). Os dados foram organizados em gráficos e tabelas por meio de softwares de edição de textos e planilhas.

Posteriormente, foram analisados documentos sobre a implantação de salas de recursos multifuncionais, formação de gestores e diretrizes que normatizam a operacionalização do AEE nos sistemas de ensino partir do ano de 2008 a 2014. A tabela 2 ilustra os documentos selecionados para análise documental e seu ementário em ordem cronológica:

Tabela 2: Materiais analisados no estudo (2008-2014)

\begin{tabular}{|c|c|}
\hline Documento & Ementa \\
\hline $\begin{array}{l}\text { Política Nacional de Educação } \\
\text { Especial na Perspectiva da } \\
\text { Educação Inclusiva (2008) }\end{array}$ & $\begin{array}{l}\text { Dispõe sobre o atendimento educacional especializado de } \\
\text { estudantes público-alvo da educação especial (PAEE). }\end{array}$ \\
\hline $\begin{array}{l}\text { Nota Técnica } \mathrm{n}^{\circ} \\
\text { 11/2010/MEC/MEC/SEESP/GAB, } \\
\text { de } 7 \text { de maio de } 2010 .\end{array}$ & $\begin{array}{l}\text { Orientações para a institucionalização na escola, da oferta do } \\
\text { atendimento educacional especializado (AEE) em salas de } \\
\text { recursos multifuncionais. }\end{array}$ \\
\hline $\begin{array}{l}\text { Decreto } \mathrm{n}^{\mathrm{o}} 7.611, \text { de } 17 \text { de } \\
\text { novembro de 2011. }\end{array}$ & $\begin{array}{l}\text { Dispõe sobre a educação especial, o atendimento educacional } \\
\text { especializado e dá outras providências. }\end{array}$ \\
\hline $\begin{array}{l}\text { Lei } \mathrm{n}^{\mathrm{o}} 12.764 \text {, de } 27 \text { de dezembro } \\
\text { de 2012: }\end{array}$ & $\begin{array}{l}\text { Institui a Política Nacional de Proteção dos Direitos da Pessoa } \\
\text { com Transtorno do Espectro Autista; e altera o } § 3 \text { o do art. } 98 \text { da } \\
\text { Lei no } 8.112 \text {, de } 11 \text { de dezembro de } 1990 \text {. }\end{array}$ \\
\hline $\begin{array}{l}\text { Lei } n^{\circ} 12.796 \text {, de } 4 \text { de abril de } \\
2013 \text {. }\end{array}$ & $\begin{array}{l}\text { Altera a Lei } \mathrm{n}^{\circ} 9.394 \text {, de } 20 \text { de dezembro de 1996, que } \\
\text { estabelece as diretrizes e bases da educação nacional, para } \\
\text { dispor sobre a formação dos profissionais da educação e dar } \\
\text { outras providências. Brasília: Planalto Central, } 2013 \text {. }\end{array}$ \\
\hline $\begin{array}{l}\text { Lei } n^{\circ} 13.005 \text {, de } 25 \text { de junho de } \\
2014\end{array}$ & $\begin{array}{l}\text { Aprova o Plano Nacional de Educação (PNE) e dá outras } \\
\text { providências. }\end{array}$ \\
\hline
\end{tabular}

Fonte: Elaboração própria.

Os dados sobre o perfil e caracterização dos gestores foram disponibilizados pela SEMED, por intermédio do envio de Parecer Técnico da Gerência de Educação Especial e Dados do Departamento de Gestão Escolar da secretaria.

\section{Resultados e Discussões}

Apresentamos os resultados sintetizados por meio das seguintes categorias temáticas: (a) caracterização geral dos gestores; (b) formas de ingresso no cargo; (c) formação inicial dos gestores; (d) formação dos gestores em nível de pós-graduação; e, 
(e) por uma política de formação de gestores para a Educação Inclusiva.

\section{Caracterização geral dos gestores}

Com base em dados do Cadastro Escolar disponível no sítio eletrônico, a Secretaria dispõe atualmente de 487 (quatrocentas e oitenta e sete) escolas e gestores. Quanto ao gênero dos gestores da Secretaria da Educação, foi possível verificar no estudo que há uma predominância de mulheres atuando como gestores, como pode ser observado no Gráfico 1:

Gráfico 1 - Gestores da Secretaria Municipal de Educação por Gênero (Masculino e Feminino)

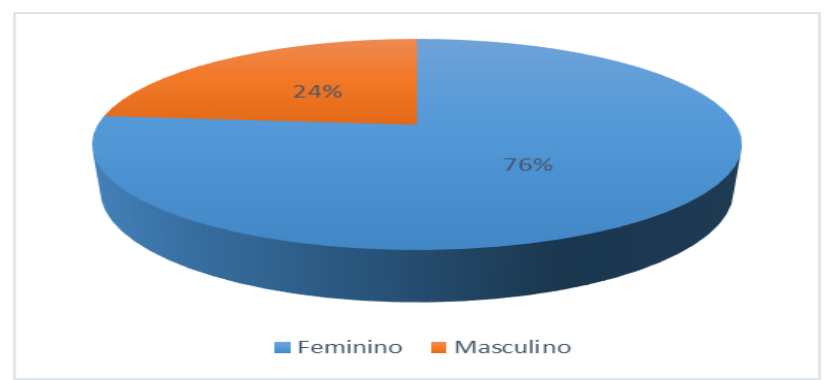

Fonte: Elaboração própria, com base nos dados do estudo.

Como pode ser observado no Gráfico 1, quando se refere ao gênero dos gestores da Secretaria, 115 (cento e quinze) gestores são do sexo masculino e 372 (trezentas e setenta e dois) são do sexo feminino, o que representa que $76 \%$ são do sexo feminino e $24 \%$ do sexo masculino. Conforme pode-se observar no estudo, o cargo de gestor ainda é ocupado por mais mulheres que homens sendo prevalente em mais de $50 \%$ nas zonas distritais.

\section{Formas de ingresso no Cargo}

Na Secretaria Municipal de Educação ainda não há editais de seleção para a composição do cargo de gestor e nem Concurso Público de Provas ou Provas e Títulos, como ocorre em outros municípios do Brasil. Na maioria das vezes trata-se de servidores públicos que ingressaram como pedagogos ou professores das diferentes 
etapas da Educação Básica e foram indicados pela Secretaria de Educação para assunção do cargo.

Quanto às formas de ingresso no cargo, a tabela 3 apresenta as informações acerca de servidores estatutários, temporários e formas de ingresso não disponibilizadas por informações da secretaria ou informações incompletas, disponíveis no item não há informações.

Tabela 3 - Informações sobre as formas de acesso ao cargo de gestor

\begin{tabular}{cccc}
\hline Total & Estatutário & Temporário & Não há informações \\
\hline 487 & 451 & 5 & 31
\end{tabular}

Fonte: Elaboração própria, com base nos dados da pesquisa.

Dos 487 (quatrocentos e oitenta e sete) gestores que atualmente ocupam o cargo, 451 (quatrocentos e cinquenta e um) são servidores públicos que ingressaram mediante Concurso Público de Provas ou Provas e Títulos, 5 (cinco) são empregados temporários e quanto ao último quadro não foi possível obter informações de 31 (trinta e um) gestores (SEMED, 2014).

Sendo assim, os dados da tabela 3 apontam que do total de 487 gestores, 93\% são servidores estatutários, $1 \%$ temporário e dos outros $6 \%$ não obtivemos informações. Foi possível verificar no estudo que os cinco ocupantes dos cargos de gestores temporários estavam lotados na zona distrital ribeirinha.

A Lei de Diretrizes e Bases da Educação Nacional (BRASIL, 1996) estabelece em seus artigos 14 e 15 que os sistemas de ensino definirão as normas de gestão democrática do ensino público na Educação Básica, por meio dos seguintes princípios: (a) participação dos profissionais da educação na elaboração do projeto pedagógico da escola; e (b) participação das comunidades escolar e local em conselhos escolares ou equivalentes. Garante-se na legislação educacional que os sistemas de ensino assegurem às escolas “[...] progressivos graus de autonomia pedagógica e administrativa e de gestão financeira [...]” (BRASIL, 1996, art. 14).

Com base no texto da lei que define as diretrizes e bases da educação nacional se pode observar que pouco é estabelecido sobre os critérios de admissão do gestor para o cargo. Entretanto, prevê-se na LDB que os sistemas de ensino devem assegurar às unidades escolares públicas "graus de autonomia pedagógica e administrativa e de gestão financeira". No entanto, é preocupante que parte dos gestores do município não 
sejam contratados em regime estatutário e sim temporários, o que de certo modo inviabiliza a autonomia dos estabelecimentos de ensino.

Nesse contexto, se o princípio da gestão democrática já é minimizado em virtude do fato de a comunidade escolar não eleger o gestor, torna-se mais inviável ainda que a escola possua autonomia didática, administrativa e financeira se o gestor não é pertencente ao quadro efetivo de servidores públicos.

\section{Formação inicial dos gestores}

No que se refere à formação inicial dos gestores que desenvolvem serviços na Secretaria, verificou-se que os servidores tiveram formação inicial tanto em bacharelado quanto em licenciatura em diversos cursos, dos quais podemos citar: (a) turismo; (b) psicologia; (c) ciências biológicas; (d) administração; (e) estudos sociais; (f) pedagogia; (g) ensino religioso; (h) letras; (i) geografia; (j) educação artística; (l) filosofia, dentre outros.

Para apresentação dos dados dividimos em dois grupos, o primeiro grupo composto por cursos em bacharelado e o segundo grupo composto por cursos de licenciatura e formação pedagógica. Os dados do primeiro grupo podem ser melhor visualizados no Gráfico 2:

\section{Gráfico 2 - Formação inicial dos gestores (Grupo 1 - Bacharelado)}

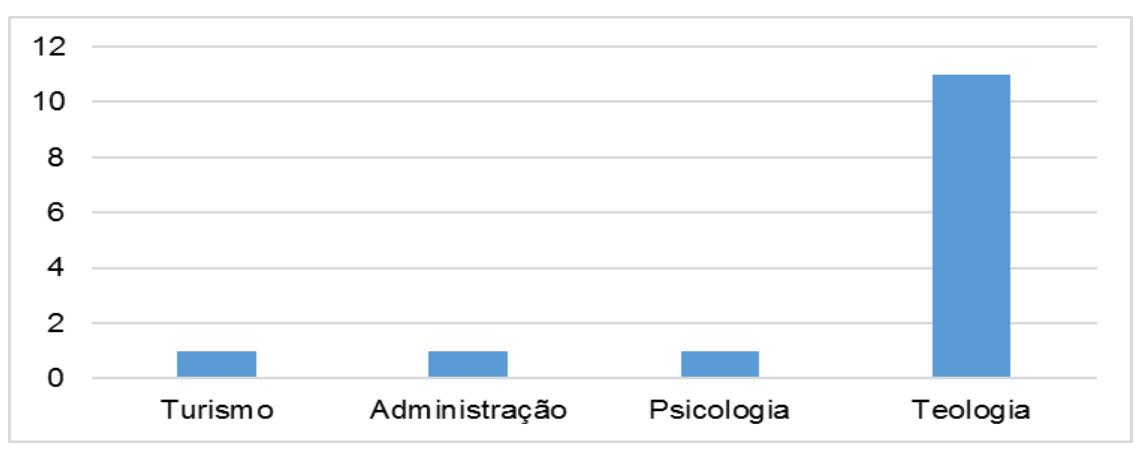

Fonte: Elaboração própria, com base nos dados da pesquisa.

A partir dos dados obtidos na pesquisa, ilustrados no Gráfico 2, foi possível verificar gestores sem formação inicial na área pedagógica que atuam no cargo de gestor nas diferentes regiões distritais. Verificou-se um gestor com formação em 
Turismo, um em Administração, um em Psicologia e onze gestores com formação inicial em Teologia.

Ao comparar a realidade da formação dos gestores da rede na capital amazonense com a Lei de Diretrizes e Bases (BRASIL, 1996) pode-se observar certa incongruência entre o que é apresentado na lei e o que ocorre na prática:

Art. 61. Consideram-se profissionais da educação escolar básica os que, nela estando em efetivo exercício e tendo sido formados em cursos reconhecidos, são:

I - professores habilitados em nível médio ou superior para a docência na educação infantil e nos ensinos fundamental e médio;

II - trabalhadores em educação portadores de diploma de pedagogia, com habilitação em administração, planejamento, supervisão, inspeção e orientação educacional, bem como com títulos de mestrado ou doutorado nas mesmas áreas;

III - trabalhadores em educação, portadores de diploma de curso técnico ou superior em área pedagógica ou afim.

Parágrafo único. A formação dos profissionais da educação, de modo a atender às especificidades do exercício de suas atividades, bem como aos objetivos das diferentes etapas e modalidades da educação básica, terá como fundamentos:

I - a presença de sólida formação básica, que propicie o conhecimento dos fundamentos científicos e sociais de suas competências de trabalho;

II - a associação entre teorias e práticas, mediante estágios supervisionados e capacitação em serviço;

III - o aproveitamento da formação e experiências anteriores, em instituições de ensino e em outras atividades. (BRASIL, 1996, art. 61).

Mesmo que a legislação educacional não aponte a obrigatoriedade da formação dos gestores em cursos na área pedagógica, ela permite que a formação dos "trabalhadores em educação" seja em curso técnico ou superior em área pedagógica ou afim. Nessa perspectiva torna-se necessário problematizar: (a) $\mathrm{O}$ que seria um curso técnico/superior em área afim da pedagógica? (b) A formação nos bacharelados propicia conhecimento dos fundamentos científicos e sociais na área educacional? (c) A formação inicial dos gestores permite que sejam atendidas as especificidades do exercício da gestão da escola?

Quanto ao segundo grupo, de gestores com formação inicial em pedagogia e nas demais licenciaturas, os dados podem ser observados no Gráfico 3: 
Gráfico 3 - Formação Inicial dos Gestores (Grupo 2 - Licenciatura e/ou formação pedagógica)

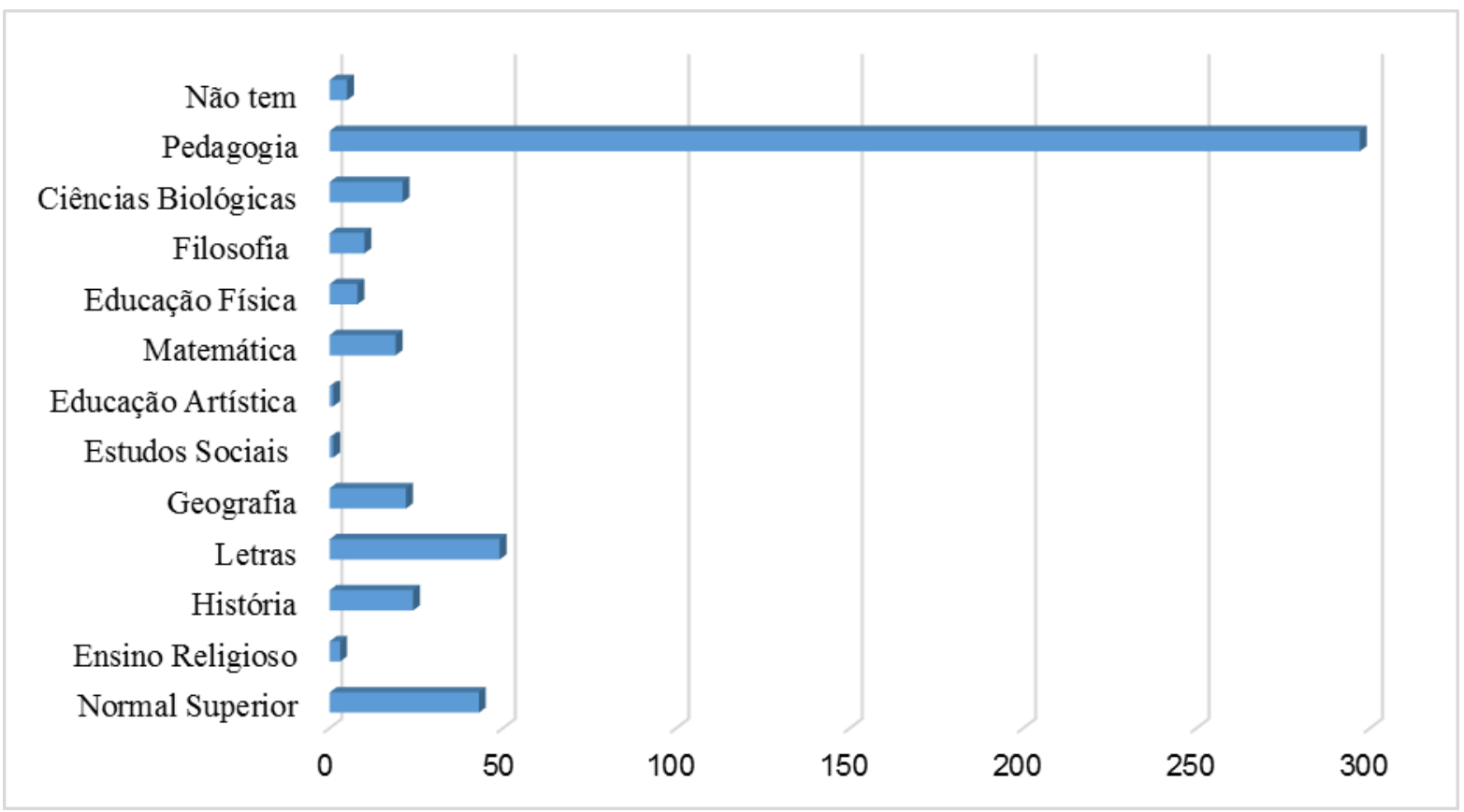

Fonte: Elaboração própria, com base nos dados da pesquisa.

A partir dos dados da pesquisa, foi possível verificar os seguintes dados: (a) 5 dos gestores não possuem graduação; (b) 297 possuem graduação em Pedagogia; (c) 21 em Ciências Naturais ou Biológicas; (d) 10 em Filosofia; (e) 8 em Educação Física; (f) 19 em Matemática; (g) 1 em Educação Artística; (h) 1 em Estudos Sociais; (i) 22 em geografia; (j) 49 em Letras; (l) 24 em História; (m) 3 em Ensino Religioso, e; (n) 43 possuem formação inicial no Curso Normal Superior.

Com base nas informações obtidas a partir do estudo foi possível verificar que dos 487 (quatrocentos e oitenta e sete) gestores da Secretaria, apenas cinco não possuem formação em nível superior. No entanto, acerca da variável dos gestores que não possuem formação inicial na área pedagógica, torna-se necessário questionar as formas de ingresso e acesso ao cargo.

Acreditamos que é fundamental no processo de democratização da escola pública a revisão da indicação pelo executivo aos cargos de direção das escolas. Assim como, se faz necessário a formação pedagógica dos diretores para a atuação junto aos professores, coordenadores pedagógicos e demais profissionais da educação.

Segundo a Lei de Diretrizes e Bases - LDB (BRASIL, 1996), em redação dada por meio da Lei $n^{\circ} 12.796 / 2013$, assegura-se no artigo 14 que os sistemas de ensino 
definirão as normas da gestão democrática do ensino público na educação básica, de acordo com as suas peculiaridades e conforme os seguintes princípios: (a) participação dos profissionais da educação na elaboração do projeto pedagógico da escola; e, (b) participação das comunidades escolar e local em conselhos escolares ou equivalentes (BRASIL, 1996, art. 14).

Precisa-se também enfatizar que conforme a atual legislação, os gestores que atuam sem formação na área não são denominados profissionais da educação. Acreditase e recomenda-se que os gestores que atuem sem formação inicial na área possam cursar licenciaturas e ações de formação continuada na área de atuação para que os requisitos para atuação previsto na LDB sejam alcançados.

Entende-se que a formação inicial e/ou continuada para a atuação junto a estudantes PAEE é um fator preponderante para o sucesso da inclusão escolar. Vale salientar que esse requisito não é imprescindível mas pode potencializar o acesso, a permanência e o sucesso escolar de estudantes PAEE.

\section{Formação dos gestores em nível de pós-graduação}

De acordo com artigo 44, inciso III da LDB, os cursos de pós-graduação compreendem programas de mestrado e doutorado, cursos de especialização, aperfeiçoamento e outros "[...] abertos a candidatos diplomados em cursos de graduação e que atendam às exigências das instituições de ensino" (BRASIL, 1996, art. 44, inciso III). A legislação também denomina profissionais da educação os trabalhadores portadores de títulos de mestres e doutores na área de educação que possuam formação adequada em cursos stricto sensu.

Ao analisarmos os dados relacionados aos gestores que atuam na rede municipal de ensino, principalmente com foco na formação inicial e continuada, observamos os seguintes dados, ilustrados no Gráfico 4: 
Gráfico 4: Formação Inicial em Graduação e Continuada em Pós-Graduação (Lato e Stricto Sensu)

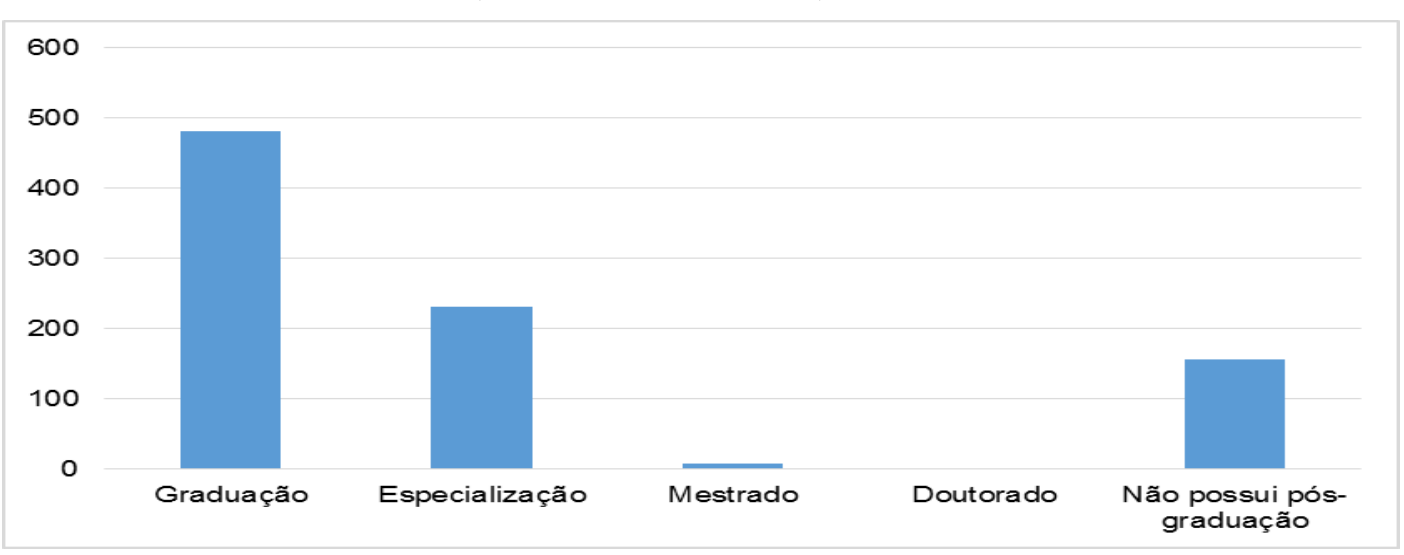

Fonte: Elaboração própria, com base nos dados da pesquisa.

A problemática da formação inicial é de certo modo inexpressiva, pois, apenas cinco dos gestores da Secretaria não possuam curso de graduação. No entanto, alguns dos gestores não possuíam cursos de formação pedagógica ou mesmo licenciatura para atuação nos cargos, como pode ser observado no Gráfico 4.

Com base nos dados verificou-se: (a) 482 (quatrocentos e oitenta e dois) possuem graduação; (b) 323 (trezentos e vinte e três) possuem curso de especialização ou pós-graduação lato-sensu; (c) 7 (sete) possuem mestrado em educação e outras áreas; (d) nenhum possui doutorado e; (e) 157 (cento e cinquenta e sete) gestores não possuem pós-graduação lato ou stricto sensu.

A partir disso, os resultados são divididos em dois grupos, o primeiro grupo apresenta os cursos em nível de pós-graduação stricto sensu e o segundo grupo apresenta os cursos de pós-graduação lato sensu. Os dados a serem apresentados precisam ser observados a partir da perspectiva de consolidação dos conhecimentos adquiridos na formação inicial. A Tabela 4 apresenta os cursos que consolidaram a formação em nível de pós-graduação stricto sensu dos gestores:

Tabela 4 - Formação dos gestores em Pós-Graduação Stricto Sensu.

\begin{tabular}{llc}
\hline \multicolumn{1}{c}{ Curso } & Nível de Pós-graduação & $\begin{array}{c}\text { Gestores } \\
\text { Titulados }\end{array}$ \\
\hline Educação & Stricto Sensu & 2 \\
\hline Ensino de Ciências na Amazônia & Stricto Sensu & 1 \\
\hline Sociedade e Cultura na Amazônia & Stricto Sensu & 1 \\
\hline Desenvolvimento Sustentável & Stricto Sensu & 2 \\
\hline Biotecnologia & Stricto Sensu & 1
\end{tabular}

Fonte: Elaboração própria, com base nos dados da pesquisa. 
Com base nos dados do estudo verificou-se a titulação dos gestores nas áreas iniciais de formação, a partir de pesquisa desenvolvida nas seguintes áreas do conhecimento: (a) educação; (b) ensino de ciências; (c) sociedade e cultura; (d) desenvolvimento sustentável e; (e) biotecnologia. No tocante aos cursos de pósgraduação lato sensu que consolidaram a formação dos gestores atuantes na Secretaria de Educação, são apresentados os seguintes dados na Tabela 5:

Tabela 5 - Formação dos Gestores em Curso de Pós-Graduação Lato Sensu

\begin{tabular}{llc}
\hline \multicolumn{1}{c}{ Curso } & Nível & $\begin{array}{c}\text { Quantitativo de } \\
\text { Gestores }\end{array}$ \\
\hline Gestão Escolar/Supervisão e Administração da Educação & Lato Sensu & 225 \\
\hline Psicopedagogia & Lato Sensu & 49 \\
\hline Psicomotricidade & Lato Sensu & 2 \\
\hline Metodologia/Didática/Docência do Ensino Superior & Lato Sensu & 35 \\
\hline Docência nas Séries Iniciais do Ensino Fundamental & Lato Sensu & 12 \\
\hline Educação Infantil & Lato Sensu & 9 \\
\hline Metodologia do Ensino de História & Lato Sensu & 4 \\
\hline História e Geografia & Lato Sensu & 1 \\
\hline Educação Ambiental & Lato Sensu & 3 \\
\hline EJA/Ensino Profissional e Tecnológico & Lato Sensu & 2 \\
\hline Literatura Brasileira Moderna e Pós-Moderna & Lato Sensu & 1 \\
\hline Educação Artística & Lato Sensu & 1 \\
\hline Língua Portuguesa & Lato Sensu & 7 \\
\hline Metodologia do Ensino de Geografia & Lato Sensu & 1 \\
\hline Educação Matemática & Lato Sensu & 4 \\
\hline Geografia da Amazônia Brasileira & Lato Sensu & 4 \\
\hline Gestão de Pessoas/RH & Lato Sensu & 2 \\
\hline Educação Especial/AEE & Lato Sensu & 2 \\
\hline Produção da Qualidade Total & Lato Sensu & 1 \\
\hline Fonte: Elaborañ prôpra com base nos & & \\
\hline
\end{tabular}

Fonte: Elaboração própria, com base nos dados da pesquisa.

A partir dos dados verificou-se grande expressividade de gestores que cursaram especialização nas áreas de gestão da educação (225), seguidos de Psicopedagogia (49), Docência do Ensino Superior (35), Docência nas Séries Iniciais do Ensino Fundamental (12), Educação Infantil (9), Língua Portuguesa (7), Metodologia do Ensino de História (4), Educação Matemática (4), Geografia da Amazônia Brasileira (4) e Educação Ambiental (3).

Os demais gestores cursaram especialização nas áreas Educação de Jovens e Adultos (EJA) e Ensino Profissional e Tecnológico (2), Literatura (1), Gestão de 
Pessoas e Recursos Humanos (2), Educação Especial (2), Educação Artística (1), Metodologia do ensino de geografia (1) e Produção da Qualidade Total (2).

Nessa perspectiva, pode-se compreender que muitos gestores continuaram seus estudos nas áreas de formação inicial. $\mathrm{Na}$ área de educação especial apenas dois gestores possuíam cursos de especialização na área. Nesse contexto, torna-se necessário investir na formação continuada desses profissionais que ainda não foram contemplados com cursos de pós-graduação lato sensu ou stricto sensu, de modo que haja maior qualificação destes profissionais para a consolidação de sistemas de ensino inclusivos.

\section{Por uma política de formação de gestores para a Educação Inclusiva}

Com base nos dados fornecidos pela Secretaria Municipal de Educação foi possível visualizar um panorama geral sobre a formação continuada de gestores da rede municipal e aspectos como gênero, formação inicial, formação continuada e formas de ingresso no cargo. Acreditamos que esses dados possibilitarão tanto à SEMED a institucionalização de mais ações para a formação desses gestores quanto aos pesquisadores da área, o preenchimento de lacunas presentes na área da pesquisa.

A problemática da formação de recursos humanos para a educação especial é visualizada na literatura sobre a temática em diversas regiões do Brasil. Verificou-se, que há muitos trabalhos na região Amazônica que evidenciam a formação docente para atuação na diversidade (MATOS, 2008; MARQUES, 2010; VINENTE, 2012), mas não se tem conhecimento de estudos específicos que tratam sobre a formação de gestores.

No âmbito do MEC, o Programa Educação Inclusiva: direito à Diversidade promoveu a formação continuada de gestores e educadores das redes estaduais e municipais de ensino. O tipo de formação baseou-se em assessoria pedagógica e palestras, além disso, foram oferecidos cursos de pós-graduação lato sensu e cursos de curta duração.

O objetivo do programa consistiu em que as redes atendessem com qualidade e incluíssem nas classes comuns do ensino regular os alunos PAEE. Segundo dados divulgados pelo MEC, durante o período de 2003 a 2007, o programa atendeu 94.695 profissionais da educação com a participação de 5.564 municípios.

Outra iniciativa do MEC para a formação de recursos humanos para a inclusão escolar é o Programa Implantação de Salas de Recursos Multifuncionais, que vem 
legitimando a necessidade de institucionalização do AEE no projeto político pedagógico da escola. Tal Programa foi instituído pela Portaria Ministerial $n^{\circ} 13 / 2007$, integrando o Plano de Desenvolvimento da Educação (PDE) e o Plano Nacional dos Direitos da Pessoa com Deficiência - Viver sem Limites, instituído pelo Decreto n ${ }^{\circ}$ 7.612/2011.

O Decreto $\mathrm{n}^{\mathrm{o}} 7.611$, de 17 de novembro de 2011, ao alterar o Decreto $\mathrm{n}^{\mathrm{o}}$ 6253, de 2007 garantindo no artigo $9^{\circ}$ que "para efeito da distribuição dos recursos do FUNDEB, será admitida a dupla matrícula dos estudantes da educação regular da rede pública que recebem atendimento educacional especializado" (BRASIL, 20007, art. $9^{\circ}$ A). Essa dupla matrícula implica o cômputo do estudante tanto na educação regular da rede pública, quanto no AEE.

Sendo o gestor um dos profissionais que juntamente com os outros membros do Conselho Escolar atuam na gerência desses recursos, acreditamos que o bom uso desses recursos para a promoção de modificações no espaço escolar e outras necessidades desses educandos possibilitará melhores resultados nos índices escolares e possibilitará não somente o acesso desses estudantes à escola, mas também a permanência e aprendizagem.

O Decreto $\mathrm{n}^{\circ} 7.611$, de 17 de novembro de 2011 traz em seu artigo $5^{\circ}$ e inciso IV a necessidade e possibilidade de "formação de gestores, educadores e demais profissionais da escola para a educação na perspectiva da educação inclusiva" (BRASIL, 2011, art. 5, inciso IV). Não defendemos que todos os professores da rede possuam formação continuada em educação especial para a efetivação da oferta do AEE no sistema de ensino, entretanto, acreditamos que a ausência da sensibilização dos gestores quanto ao tema em tela, torna-se uma barreira para a garantia da efetivação do direito de todos a educação.

$\mathrm{O}$ artigo $7^{\circ}$ da Lei $\mathrm{n}^{\circ} 12.764$, de 27 de dezembro de 2012, reconhece os direitos de escolarização obrigatória e gratuita dos estudantes com transtornos do espectro autista e outras deficiências ${ }^{4}$. De acordo com artigo $7^{\circ}$ dessa lei, "o gestor escolar, ou autoridade competente, que recusar a matrícula de aluno com transtorno do espectro autista, ou qualquer outro tipo de deficiência, será punido com multa de 3 (três) a 20 (vinte) salários-mínimos". Nessa perspectiva, acreditamos que ao menos no plano jurídico já avançamos no sentido de garantir a matrícula de estudantes PAEE nos

\footnotetext{
${ }^{4}$ Destacamos que por mais que no âmbito da legislação educacional os estudantes com transtorno do espectro autista estejam inseridos no PAEE, categoria de estudantes com transtornos globais do desenvolvimento, a Lei $n^{\circ} 12.764$ define esses estudantes como deficientes (BRASIL, 2012).
} 
sistemas de ensino, não cerceando o direito ao acesso, permanência e aprendizagem desses estudantes.

A formação de gestores implica o reconhecimento das necessidades educacionais a serem atendidas pelos sistemas de ensino e a qualificação profissional para atuação na diversidade. É perceptível que na contemporaneidade, o Brasil tem definido políticas públicas e criado instrumentos legais que garantem os direitos dos estudantes PAEE, no entanto, apenas isso não é suficiente.

\section{Considerações Finais}

Com base nos resultados do estudo foi possível identificar a distribuição de salas de recursos multifuncionais no estado do Amazonas e na rede municipal de ensino da cidade de Manaus, visando a garantia do acesso, permanência e sucesso escolar de estudantes PAEE. Acreditamos que somente a formação inicial de professores para o AEE não é suficiente para que a o processo de inclusão escolar seja efetivado, demandando esforços do Poder Público também para a formação dos gestores educacionais.

Por meio dos documentos publicados pelo Ministério da Educação foi possível discutir as orientações para a formação de gestores no sentido de que atuem na perspectiva da educação inclusiva. Os dados focalizam a necessidade de formação inicial e continuada dos gestores e demais profissionais da educação para a efetivação do acesso e permanência de estudantes PAEE na escola.

Os programas e projetos, bem como ações governamentais encontradas foram discutidas a partir da legislação educacional. Nessa perspectiva, tais programas têm evidenciado cursos de curta duração e à distância, bem como palestras dos quais os participantes tornam-se multiplicadores do que foi trabalhado nos programas de formação. Nessa ótica, o Estado racionaliza custo e atende mais profissionais. Sendo assim é necessário que esse atual modelo de formação seja amplamente discutido e avaliado para que possibilite resultados mais significativos e consistentes.

Quanto à concepção de inclusão escolar contida nos documentos analisados, verificou-se a substituição do modelo de educação especial clínico para a perspectiva do AEE, a partir de uma escola inclusiva. É claro que a transformação do espaço escolar ainda se encontra em operacionalização e os resultados de outros trabalhos apontam 
para a mesma direção (GARCIA; MICHELS, 2011; VINENTE, 2012; MATOS; MENDES, 2012; LAGO; ALMEIDA, 2014).

É possível perceber que com investimentos das esferas governamentais, com a formação de professores, gestores e demais profissionais para uma escola inclusiva e intensa participação dos entes federados na formulação e implementação das políticas de inclusão escolar, cria-se se um espaço mais democrático e consistente para que todos os estudantes, independentemente de suas especificidades sejam atendidos.

Os resultados do estudo consequentemente possibilitaram a elaboração de um panorama de como vem se efetivando na região Amazônica as políticas de inclusão e as possibilidades de superação dos desafios presentes na diversidade regional.

O presente estudo pretendeu proporcionar o aprofundamento da legislação brasileira sobre educação especial, bem como buscou sistematizar os dados relacionados ao município de Manaus, a partir da leitura crítica sobre a política de formação de gestores na perspectiva da educação inclusiva.

Não esgotamos aqui a avaliação do processo de implementação da política de educação especial na perspectiva da educação inclusiva na capital amazonense. Reconhecemos que ainda há lacunas a serem preenchidas por pesquisas na região amazônica que se debrucem a realizar levantamentos sobre as demandas de formação, comparar as diferentes formas de gestão da escola nas diferentes zonas distritais da rede municipal, e avaliar a relação entre docentes, gestores e demais profissionais da educação no que se refere ao suporte escolar de estudantes PAEE.

Portanto, precisamos avançar ainda mais na consolidação dos dispositivos legais e no desenvolvimento de práticas mais inclusivas. Consequentemente, cada etapa da investigação permitiu a aquisição de conhecimento sobre a realidade educacional nacional e regional, ao trazer como foco o desenvolvimento de ações para a consolidação das políticas inclusivas no cenário amazônico e efetivação da formação de gestores e demais profissionais para o AEE.

\section{Referências}

BRASIL. Constituição da República Federativa do Brasil (1988). Disponível em: <www.planalto.gov.br>. Acesso em: 15 abr. 2015.

Decreto $\mathrm{n}^{\circ}$ 6.253, de 13 de novembro de 2007: Dispõe sobre o Fundo de Manutenção e Desenvolvimento da Educação Básica e de Valorização dos Profissionais da Educação - FUNDEB, regulamenta a Lei no 11.494, de 20 de junho de 2007, e dá 
outras providências. Disponível em: <https://www.planalto.gov.br/ccivil_03/_Ato20072010/2007/Decreto/D6253.htm\#art9a.>. Acesso em: 24 out. 2015.

Decreto no 7.611, de 17 de novembro de 2011: dispõe sobre a educação especial, o atendimento educacional especializado e dá outras providências. Disponível em: 〈www.planalto.gov.br〉. Acesso em: 10 mar. 2015.

Lei $n^{0}$ 12.764, de 27 de dezembro de 2012: Institui a Política Nacional de Proteção dos Direitos da Pessoa com Transtorno do Espectro Autista; e altera o § 3o do art. 98 da Lei no 8.112, de 11 de dezembro de 1990. Disponível em: <http://www.planalto.gov.br/ccivil_03/_Ato2011-2014/2012/Lei/L12764.htm>. Acesso em: 2 out. 2015.

Lei $n^{\circ}$ 12.796, de 4 de abril de 2013: altera a Lei $n^{\circ}$ 9.394, de 20 de dezembro de 1996, que estabelece as diretrizes e bases da educação nacional, para dispor sobre a formação dos profissionais da educação e dar outras providências. Brasília: Planalto Central, 2013.

Lei no 13.005, de 25 de junho de 2014: aprova o Plano Nacional de Educação e dá outras providências. Brasília: Senado Federal, 2014.

Lei no 8.069, de 13 de julho de 1990: dispõe sobre o Estatuto da Criança e do Adolescente e dá outras providências. Disponível em: <https://www.planalto.gov.br/ccivil_03/_ato2011-2014/2011/decreto/d7611.htm $>$.

Acesso em 24 out. 2015.

Lei $n^{0}$ 9.394/1996, de 20 de dezembro de 1996: dispõe sobre as diretrizes e bases da educação nacional. Disponível em: <http://www.planalto.gov.br/>. Acesso em: 22 mar. 2015.

Manual de orientação: Programa de Implantação de Salas de Recursos Multifuncionais. Brasília: MEC, 2010.

Nota Técnica SEESP/GAB $\mathbf{n}^{\mathbf{0}} \mathbf{1 1 / 2 0 1 0}$, de 7 de maio de 2010: orientações para a institucionalização da oferta de AEE em salas de recursos multifuncionais implantadas nas escolas regulares. Disponível em: 〈www.mec.gov.br $\rangle$. Acesso em: jul. 2015.

Política Nacional de Educação Especial na Perspectiva da Educação Inclusiva. Brasília: MEC/SEESP, 2008. Disponível em: 〈www.mec.gov.br〉. Acesso em: 20 abr. 2015.

FAZENDA, I. (Org.). Metodologia da pesquisa educacional. 11. ed. São Paulo: Cortez, 2008.

GARCIA, R. M. C.; MICHELS, M. H. A Política de Educação Especial no Brasil (1991-2011): uma análise da produção do GT 15 - Educação Especial da ANPED. Revista Brasileira de Educação Especial. Marília. v.17, p. 105-124, mai./ago., 2011.

IBGE. Instituto Brasileiro de Geografia e Estatística. Censo Demográfico (2010): informações do município de Manaus/AM. Disponível em: $\langle$ http://www.cidades.ibge.gov.br/xtras/perfil.php?lang=\&codmun=130260 >. Acesso em 24 set. 2015. 
INEP. Instituto Nacional de Estudos e Pesquisas Anísio Teixeira. Censo Escolar de 2013. Disponível em: <www.inep.gov.br>. Acesso em: 05 mar. 2015.

LAGO, D. C.; ALMEIDA, M. A. A política de inclusão escolar de uma rede de ensino municipal: concepções de um grupo de professores. Práxis Educacional. Vitória da Conquista, v. 10, n. 16, p. 61-80, jan./jun., 2014.

LIMA, W. G. Política pública: discussão de conceitos. Interface (Porto Nacional). n. $5,2012$.

MANAUS. Lei Delegada $n^{\circ}$ 13, de 31 de julho de 2013: dispõe sobre a estrutura organizacional da Secretaria Municipal de Educação - SEMED, suas finalidade e competências, fixa seu quadro de cargos comissionados e dá outras providências. Disponível em: <http://semed.manaus.am.gov.br/estrutura-organizacional/>. Acesso em 24 out. 2015.

MARQUES, M. P. S. D. O Acesso de Pessoas com Deficiência ao Sistema Público de Ensino de Manaus na Percepção dos Professores. Tese (Doutorado). Faculdade de Filosofia, Ciências e Letras. Universidade de São Paulo, Ribeirão Preto, 2010.

MATOS, M. A. S. Cidadania, diversidade e educação inclusiva: um diálogo entre a teoria e a prática na rede municipal de Manaus. Porto Alegre, 2008. 229f. Tese (Doutorado em Educação) - Universidade Federal do Rio Grande do Sul. Faculdade de Educação. Programa de Pós-Graduação em Educação. Porto Alegre, 2008.

MATOS, S. N.; MENDES, E. G. Demandas de professores decorrentes da inclusão escolar. Revista Brasileira de Educação Especial, v. 21, n. 1. Marilia, jan./mar., 2015.

MEC. Ministério da Educação. Educação Inclusiva: apresentação. Brasília: SECADI, 2014. Disponível em: <http://portal.mec.gov.br>. Acesso em: 23 mar. 2015.

OLIVEIRA, S. S. B.; OLIVEIRA, S. E. B. A arte da pesquisa: os limites na construção teórico-metodológica. In: XX EPENN - Encontro Nacional de Pesquisa Educacional do Norte e Nordeste. Manaus: Valer, 2011.

SANCHEZ GAMBOA, S. S. Fundamentos para a investigação: pressupostos epistemológicos que orientam o pesquisador. Bogotá: Editorial Magistério, 1998.

SEMED. Secretaria Municipal de Educação da Cidade de Manaus. Cadastro Escolar Departamento de Gestão Educacional, 2014. Disponível em: <http://semed.manaus.am.gov.br/>. Acesso em: 10 abr. 2015.

VILARONGA, C. A. R.; MENDES, E. G. Ensino colaborativo para o apoio à inclusão escolar: práticas colaborativas entre os professores. Revista Brasileira de Estudos Pedagógicos. v. 95, n. 239, Brasília, jan./abr., 2014.

VINENTE, S. O atendimento escolar do aluno com paralisia cerebral na rede municipal de ensino em Manaus: a práxis pedagógica no contexto da diversidade. In: MATOS, M. A. S. Educação especial, políticas públicas e inclusão: desafios da prática e contribuições da pesquisa. Manaus: Vitória, 2012. 


\section{Como referenciar este artigo}

VINENTE, Samuel; OLIVEIRA, Sônia Selena Baçal de. Implementação do Atendimento Educacional Especializado e a formação de gestores na capital amazonense. Revista Ibero-Americana de Estudos em Educação, Araraquara, v.12, n.1. p. 507-528, 2017. Disponível em: 〈http://dx.doi.org/10.21723/riaee.v12.n1.8202〉. E-ISSN: 1982-5587.

Data de submissão: nov/2015

Aprovação final: fev/2017 